\title{
Proline is biosynthesized from arginine in Staphylococcus aureus
}

\author{
David E. Townsend,$\uparrow$ Anisa Kaenjak, $\ddagger$ Radheshyam K. Jayaswal and \\ Brian J. Wilkinson
}

\author{
Author for correspondence: Brian J. Wilkinson. Tel: +1 309438 7244. Fax: +1 3094383722. \\ e-mail: bjwilkin@rs6000.cmp.ilstu.edu
}

Microbiology Group, Department of Biological Sciences, Illinois State University, Normal, Illinois 61790-4120, USA

\begin{abstract}
Staphylococcus aureus NCTC 8325 exhibited a long lag phase (11 h) when inoculated into defined medium lacking proline, that could be shortened by increasing the concentration of arginine in the medium, or by supplying ornithine. Radioactivity from $\mathrm{L}-\left[{ }^{14} \mathrm{C}\right]$ arginine, but not $\mathrm{L}-\left[{ }^{14} \mathrm{C}\right]$ glutamate was incorporated into a spot with the chromatographic mobility of $\left[{ }^{14} \mathrm{C}\right]$ proline in the pool metabolites fraction. Selection for transposon Tn917-lacz mutants impaired in arginine catabolism yielded four proline auxotrophs. Enzyme assays and precursor feeding experiments suggested that the major pathway for proline biosynthesis in $S$. aureus was from arginine via ornithine and $\Delta^{\prime}$-pyrroline 5-carboxylate, rather than from glutamate. Strain $8325 \mathrm{Pro}^{+}$, a proline prototrophic variant obtained by cultivation of 8325 in the absence of proline, accumulated $\mathrm{L}-\left[{ }^{14} \mathrm{C}\right]$ arginine from the medium at about eight times the rate of strain 8325 , suggesting its response to proline starvation was to increase arginine uptake.
\end{abstract}

Keywords: Stapbylococcus aureus, proline, arginine, transport

\section{INTRODUCTION}

Stapbylococcus aureus typically requires a complex cotíbination of amino acids and vitamins to grow in synthetic medium. Emmett \& Kloos (1975) examined the amino acid requirements of 50 strains of $S$. aureus and found that the most frequently required amino acids were arginine and valine, followed by leucine, cysteine and proline. These authors noted that a number of auxotrophic strains exhibited large isolated colonies among a reduced background of auxotrophic growth, when certain amino acids were omitted from the growth medium. These colonies were believed to be the result of spontaneous mutations in cryptic amino acid biosynthetic pathways, which allowed the cells to produce the missing amino acid. Particularly high reversion frequencies were noted when the amino acids alanine, glycine, leucine, proline, tryptophan or valine were omitted from the growth medium.

During an investigation of proline transport and its

†Present address: Idexx Laboratories, One Idexx Drive, Westbrook, ME 04092, USA.

$\ddagger$ Present address: Department of Microbiology, University of Alabama at Birmingham, Birmingham, AL 35213, USA.

Abbreviation: P5C, $\Delta^{\prime}$-pyrroline 5-carboxylate. relation to osmoregulation in $S$. aureus strain NCTC 8325 , we found a long delay in growth (at least $11 \mathrm{~h}$ ) when the strain was inoculated into defined medium lacking proline (Townsend \& Wilkinson, 1992). Subsequent studies on solid medium revealed that a majority of the cells (about $79 \%$ ) were able to grow in the absence of proline after $3 \mathrm{~d}$ of incubation at $37^{\circ} \mathrm{C}$. These results suggest that a functional proline biosynthetic pathway is present in this strain, but that it requires an unusually long period of time to become fully active.

The major pathway leading to the production of proline in bacteria has been well established for many years (Leisinger, 1987). In this pathway, glutamic acid is converted to proline in a four-step sequence involving the enzymes $\gamma$-glutamyl kinase (glutamate 5-kinase, EC 2.7.2.11), glutamate- $\gamma$-semialdehyde dehydrogenase (EC 1.2.1.41) and $\Delta^{\prime}$-pyrroline-5-carboxylate (P5C) reductase (EC 1.5.1.2) (Fig. 1). This pathway for proline biosynthesis has been established in Escherichia coli, Bacillus spp. and other bacterial species (Baumberg \& Klingel, 1993; Hayzer \& Leisinger, 1981; Leisinger, 1987), as well as the yeast Saccharomyces cerevisiae (Brandriss \& Falvey, 1992).

Proline can also be produced from arginine through the catabolism of arginine by a number of different pathways 


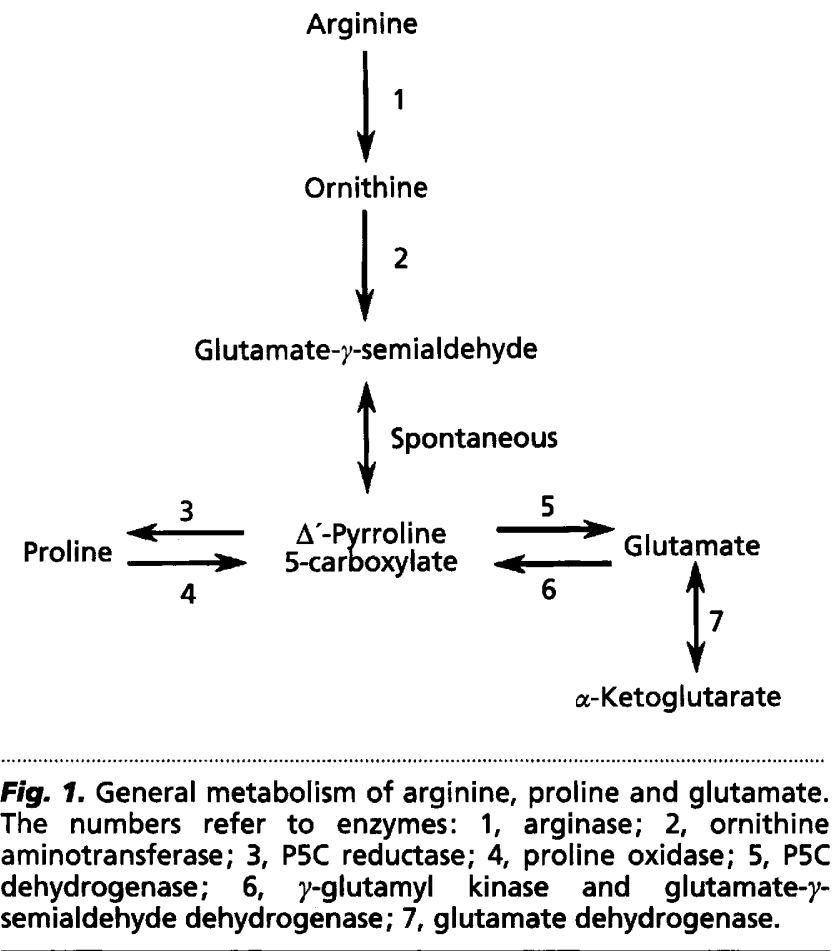

(Abdelal, 1979; Cunin et al., 1986). One such pathway, the arginase pathway, has been characterized in a number of bacteria, including Bacillus subtilis and Bacillus licheniformis (Fisher, 1993; Laishley \& Bernlohr, 1968), as well as in some eukaryotic organisms such as Sacch. cerevisiae, Aspergillus nidulans and Neurospora crassa (Fig. 1). There are three enzymes in the arginase pathway: arginase (EC 3.5.3.1), ornithine aminotransferase (ornithine-oxo-acid transaminase, EC 2.6.1.13) and P5C dehydrogenase (EC 1.5.1.12), which are involved in utilizing arginine as a source of carbon and energy (Fig. 1). Proline is formed in this pathway through the reduction of $\mathrm{P} 5 \mathrm{C}$ by $\mathrm{P} 5 \mathrm{C}$ reductase.

In this paper, we provide evidence which suggests that in $S$. aureus, proline is biosynthesized through an arginine to proline pathway rather than one which converts glutamate to proline.

\section{METHODS}

Bacterial strains. S. aureus NCTC 8325 (Novick, 1991) and strain $8325 \mathrm{Pro}^{+}$, a variant of 8325 that is prototrophic for proline (Townsend \& Wilkinson, 1992), were studied. Both strains 8325 and $8325 \mathrm{Pro}^{+}$are arginine auxotrophs, showing an absolute requirement for arginine (or ornithine). For construction of transposon-induced mutants, $S$. aureus strain ISP2018 [a derivative of 8325-4 containing plasmid pTV32, which harbours $\operatorname{Tn} 917-l a c Z$, a $5.4 \mathrm{~kb}$ transposon encoding MLS $^{r}$ (macrolide, lincosamide and streptogramin antibiotic resistance) supplied by P. A. Pattee, Iowa State University, Ames, Iowa] was used. Mutants DT105, DT112, DT115 and DT116, selected for being defective in arginine catabolism, were also studied. Southern hybridization experiments were per- formed to determine the number of transposon insertions per mutant. DNA from the mutants was digested with various restriction endonucleases, electrophoresed, blotted and probed with Tn917-lacZ. The results indicated the insertion of single copies of the transposon into the chromosome of the mutants (data not shown).

Growth conditions. Unless noted otherwise, all experiments were carried out with cells grown in a defined medium containing glycerol as the primary carbon and energy source (Townsend \& Wilkinson, 1992), but lacking $\left(\mathrm{NH}_{4}\right)_{2} \mathrm{SO}_{4}$.

Arginine uptake studies. To measure the rate of $\mathrm{L}_{-}\left[{ }^{14} \mathrm{C}\right]$ arginine uptake in exponential phase cultures of strains 8325 and 8325 $\mathrm{Pro}^{+}$, an uptake assay protocol involving membrane filtration and scintillation counting, similar to that of Townsend \& Wilkinson (1992), was used.

Isolation of transposon-induced mutants. Strain ISP2018 was grown on a plate of tryptic soy agar containing erythromycin $\left(20 \mu \mathrm{g} \mathrm{ml}^{-1}\right)$ for $2 \mathrm{~d}$ at $25^{\circ} \mathrm{C}$. This culture was then resuspended and diluted in $\mathrm{NaCl}(0.85 \%, \mathrm{w} / \mathrm{v})$, and spread onto plates of glycerol defined medium plus erythromycin $\left(20 \mu \mathrm{g} \mathrm{ml}^{-1}\right)$, or plates of tryptic soy agar containing erythromycin $\left(20 \mu \mathrm{g} \mathrm{ml}^{-1}\right)$, and grown overnight at $43^{\circ} \mathrm{C}$. Plates with about 500 colonies were replica-plated onto defined medium lacking glycerol and containing arginine $(50 \mathrm{mM})$ as the major carbon and energy source (arginine defined medium) and erythromycin $\left(20 \mu \mathrm{g} \mathrm{ml}^{-1}\right)$. In some experiments, the colonies were replicaplated onto arginine defined medium minus proline containing erythromycin $\left(20 \mu \mathrm{g} \mathrm{ml}^{-1}\right)$. After overnight incubation at $43{ }^{\circ} \mathrm{C}$, these plates were screened to identify mutants that could not grow on the selective media. Mutants that did not grow, or grew poorly on the arginine defined medium plates, but grew well on the original master plates, were retained for further study.

Isotope tracer studies. The ability of $S$. aureus to biosynthesize proline from arginine or glutamic acid was evaluated by culturing cells to late exponential phase with radiolabelled $\mathrm{L}-\left[{ }^{14} \mathrm{C}\right]$ arginine $\left(0 \cdot 19 \mu \mathrm{Ci} \mathrm{ml}{ }^{-1}\right)$ or $\mathrm{L}-\left[{ }^{14} \mathrm{C}\right]$ glutamate $(0 \cdot 036 \mu \mathrm{Ci}$ $\mathrm{ml}^{-1}$ ) and examining the intracellular pool for the presence of radiolabelled proline. The pool metabolites fraction was obtained by trichloroacetic acid extraction and subjected to paper chromatography as described by Townsend \& Wilkinson (1992).

Pool amino acid analysis. The intracellular amino acid pools of strain 8325 grown with different concentrations of arginine and glutamate were measured in late exponential phase cells. The pool metabolites fraction was obtained by trichloroacetic acid extraction as described by Christian (1961) and Graham \& Wilkinson (1992). Amino acid analysis by HPLC of phenylisothiocyanate derivatives was performed on a Waters PICO TAG column according to the method of Bildingmeyer et al. (1984). Hydroxyproline was used as an internal standard.

Arginase and ornithine aminotransferase assays. Arginase and ornithine aminotransferase activities were assayed colorimetrically as described by Harwood \& Baumberg (1977) in cells made permeable by chloroform treatment.

P5C synthesis. P5C was synthesized from hydroxylysine using the method described by Williams \& Frank (1975).

Molecular genetic procedures. DNA was isolated from $S$. aureus strains as described previously (Jayaswal et al., 1990). Plasmid isolation, Southern blot analysis and oligonucleotide labelling were performed as described by Sambrook et al. (1989). 


\section{RESULTS AND DISCUSSION}

\section{Arginine and ornithine reduce the lag associated with proline starvation}

Strain 8325 grew poorly in medium lacking proline, exhibiting a long lag phase unless the medium was supplemented with a high concentration $(5-50 \mathrm{mM})$ of arginine (Fig. 2). Other amino acids, such as glutamate, glycine, lysine or tryptophan, failed to spare the proline requirement. Ornithine $(250 \mu \mathrm{M})$ was able to substitute for both proline and arginine, and ornithine was more effective than arginine at the same concentration. The mean generation time of the culture in glycerol defined medium lacking both proline and arginine, but containing $250 \mu \mathrm{M} \mathrm{L}$-ornithine was $1 \cdot 1 \mathrm{~h}$, compared with $7.5 \mathrm{~h}$ in



Fig. 2. Influence of L-arginine on the growth of strain 8325 . Different concentrations of L-arginine were added to glycerol defined medium minus proline and growth was measured. $O$, $0.24 \mathrm{mM}$;, $5 \mathrm{mM} ; \square, 10 \mathrm{mM} ; \square, 15 \mathrm{mM} ; \Delta, 25 \mathrm{mM} ; \Delta$, $50 \mathrm{mM}$. medium lacking proline but containing $240 \mu \mathrm{M} \mathrm{L}$-arginine. Increasing the L-ornithine concentration to $25 \mathrm{mM}$ did not further increase the growth rate of the culture. These results suggest that $S$. aureus is able to synthesize proline from arginine via ornithine.

\section{Amino acid pool analysis of cultures grown in the presence of increasing concentrations of arginine or glutamate}

The intracellular amino acid pool of strain 8325 was measured. Increasing the concentration of arginine in the glycerol defined medium resulted in a significant increase in the intracellular concentrations of ornithine and proline (Table 1). The intracellular concentration of ornithine increased from $<1$ to $46 \mathrm{mM}$ when the concentration of arginine in the growth medium was increased from 0.05 to $50 \mathrm{mM}$. Under these same conditions, the intracellular concentration of proline increased from 32 to $69 \mathrm{mM}$. Increasing the glutamate content of the growth medium decreased the intracellular concentration of both of these amino acids.

\section{Incorporation of radioactivity from $\mathrm{L}-\left[{ }^{14} \mathrm{C}\right]$ arginine but not $\mathrm{L}-\left[{ }^{14} \mathrm{C}\right]$ glutamate into proline}

In a typical experiment, strain 8325 accumulated 1707 c.p.m. (mg dry wt) ${ }^{-1}$ in the pool metabolites fraction when grown in the presence of $\mathrm{L}_{-}\left[{ }^{14} \mathrm{C}\right]$ arginine. Chromatography of the pool extract indicated that about $17 \%$ of the radioactivity migrated with the same mobility as authentic proline (Fig. 3a). No spot corresponding to radioactive proline was detected in the pool metabolites fraction of $\mathrm{L}-$ $\left[{ }^{14} \mathrm{C}\right]$ glutamate-grown cultures, despite having accumulated 18596 c.p.m. (mg dry wt) $)^{-1}$ (Fig. 3b).

\section{Isolation of transposon-induced mutants defective in the arginine to proline pathway}

To further establish the biosynthesis of proline from arginine, we isolated several mutants defective in arginine catabolism that were proline auxotrophs. The growth

Table 1. Amino acid pool levels of strain 8325 grown in glycerol defined medium with different concentrations of arginine and glutamate

The values represent the results of analyses of a single batch of cells for each growth condition. The coefficient of variation for individual amino acid determinations was $\pm 5.5 \%$. Concentrations of amino acids in $\mathrm{mM}$ terms were calculated according to Graham \& Wilkinson (1992). ND, not detected.

\begin{tabular}{|lcccc|}
\hline \multirow{2}{*}{ Medium } & \multicolumn{3}{c|}{ Pool levels of amino acids $\left[\mathbf{n m o l}\left(\mathbf{m g}\right.\right.$ dry wt) $\left.{ }^{\mathbf{- 1}} ; \mathbf{( m M )}\right]$} \\
\cline { 2 - 5 } & Arginine & Glutamate & Ornithine & Proline \\
\hline 0.05 mM Arginine & $1(1)$ & $281(176)$ & ND & $50(32)$ \\
5 mM Arginine & $4(2)$ & $489(306)$ & $15(9)$ & $73(46)$ \\
50 mM Arginine & $16(10)$ & $414(249)$ & $73(46)$ & $111(69)$ \\
0.05 mM Glutamate & $1(1)$ & $140(88)$ & $7(5)$ & $59(37)$ \\
5 mM Glutamate & $1(1)$ & $228(142)$ & $3(2)$ & $43(27)$ \\
50 mM Glutamate & $3(2)$ & $172(106)$ & $1(1)$ & $24(15)$ \\
\hline
\end{tabular}




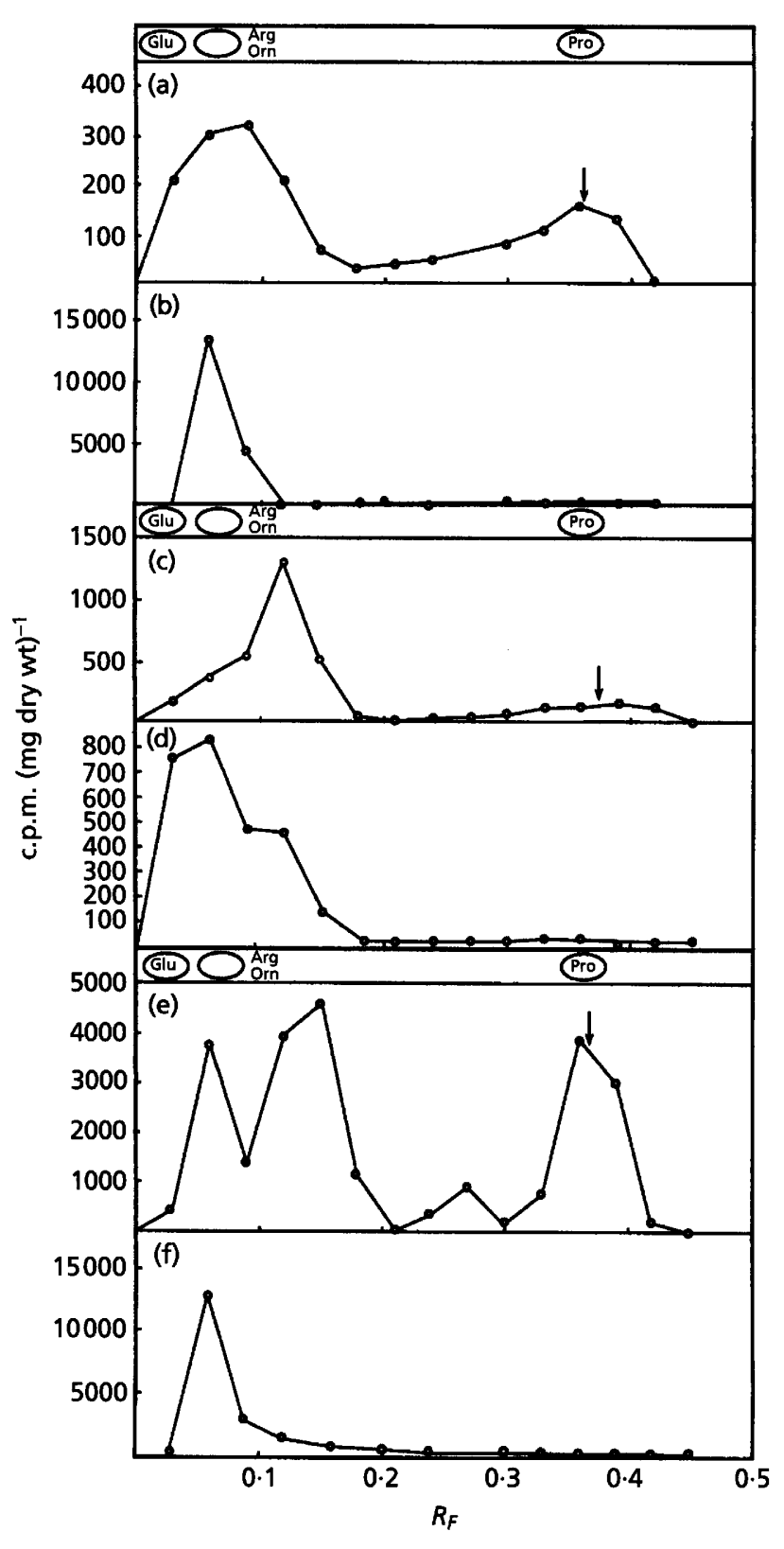

Fig. 3. Chromatography of the pool metabolites fractions of various strains after growth in the presence of $\mathrm{L}-\left[{ }^{14} \mathrm{C}\right]$ arginine or $\mathrm{L}-\left[{ }^{14} \mathrm{C}\right]$ glutamate. The migration of $\mathrm{L}-\left[{ }^{3} \mathrm{H}\right]$ proline added to the samples is indicated by the arrow. The migration of the indicated amino acids in parallel strips, detected by ninhydrin, is indicated at the top of the figure. (a) 8325 grown with L$\left[{ }^{14} \mathrm{C}\right]$ arginine; (b) 8325 grown with $\mathrm{L}-\left[{ }^{14} \mathrm{C}\right]$ glutamate; (c) DT105 grown with L- $\left[{ }^{14} \mathrm{C}\right]$ arginine; (d) DT112 grown with L$\left[{ }^{14} \mathrm{C}\right]$ arginine; (e) $8325 \mathrm{Pro}^{+}$grown with L- $\left[{ }^{14} \mathrm{C}\right]$ arginine; $(f) 8325$ Pro ${ }^{+}$grown with L- $\left[{ }^{14} \mathrm{C}\right]$ glutamate.

characteristics of the mutants on solid medium are summarized in Table 2. The auxotrophic requirement for proline of mutant DT105 was eliminated when the mutant was grown in glycerol defined medium minus proline supplemented with $50 \mathrm{mM}$ ornithine or $28.5 \mu \mathrm{M}$ P5C. This mutant was able to grow weakly in medium containing arginine as a major carbon and energy source. When $50 \mathrm{mM}$ arginine was added to glycerol defined medium lacking proline, weak growth relative to the wild-type control was observed, consistent with the weak growth observed on arginine defined medium. The growth characteristics of this mutant suggested that it was defective in arginase activity (Fig. 1).

The specific activities of arginase (Table 2) and ornithine aminotransferase of the arginase pathway were compared in strains 8325 and DT105. The results strongly suggest that strain DT105 is defective in arginase activity. This would explain why ornithine and P5C were more effective than arginine in supporting growth of this mutant in the absence of proline. Strain 8325 and DT105, and indeed all strains studied, had similar activities of ornithine aminotransferase ranging from 0.075 to $0.14 A_{\mathbf{4 4 0}}$ units $\mathrm{h}^{-1}(\mathrm{mg}$ dry $w t)^{-1}$.

The incorporation of radioactivity from $\mathrm{L}-\left[{ }^{14} \mathrm{C}\right]$ arginine into proline was determined in strain DT105 (Fig. 3c). The mutant accumulated 3712 c.p.m. (mg dry wt) ${ }^{-1}$ in its pool metabolites fraction, and chromatography indicated that $\left[{ }^{14} \mathrm{C}\right]$ proline corresponded to $7 \%$ of the total pool radioactivity, compared to $17 \%$ in strain 8325 (Fig. 3a). The low amount of $\mathrm{L}-\left[{ }^{14} \mathrm{C}\right]$ proline produced from $\mathrm{L}^{-}$ $\left[{ }^{14} \mathrm{C}\right]$ arginine may explain our results above, which show slow, weak growth of this strain in the absence of proline, after a long delay when $50 \mathrm{mM}$ arginine is present in the medium (Table 2). This suggests that a small amount of arginine may be being converted into ornithine or P5C. Given the low, but possibly significant, activity of arginase in strain DT105 (Table 2), it may be that the transposon has inserted into a promoter region, rather than the arginase structural gene. It is also possible that an alternative, slower pathway producing ornithine or $\mathrm{P} 5 \mathrm{C}$ independent of arginase, may be operating (Abdelal, 1979; Cunin et al., 1986), which can then be used to produce proline. A candidate is the deiminase pathway known to be present in Bacillus sp., lactic acid bacteria and clostridia (Fisher, 1993). This is also known as the arginine dihydrolase reaction which generates ATP by substrate level phosphorylation. This reaction has been detected in S. aureus (Krasuski, 1981). In addition, class I arginine hydroxamate-resistant mutants of $B$. subtilis also seemed to catabolize arginine, even though arginase activity was undetectable (Mountain \& Baumberg, 1980).

Three additional mutants were isolated which could not grow on arginine defined medium minus proline (DT112, DT115 and DT116). These mutants were auxotrophic for proline but could grow well with arginine as the major carbon and energy source when proline was present. The mutants were unable to grow in the absence of proline even when $50 \mathrm{mM}$ arginine, $50 \mathrm{mM}$ ornithine or $28.5 \mu \mathrm{M}$ P5C were provided in the medium. The mutants had normal arginase (Table 2) and ornithine aminotransferase activities. There was essentially no incorporation of radioactivity from $\mathbf{L}-\left[{ }^{14} \mathrm{C}\right]$ arginine into proline in strain DT112 (Fig 3d). The characteristics of these mutants suggest that they may be defective in the enzyme P5C reductase. However, all attempts to assay P5C reductase 
Table 2. Growth characteristics and arginase activities of the wild-type and proline auxotrophic mutants

\begin{tabular}{|c|c|c|c|c|c|c|}
\hline \multirow[t]{2}{*}{ Strain } & \multicolumn{5}{|c|}{ Growth on glycerol defined medium minus proline plus:* } & \multirow{2}{*}{$\begin{array}{c}\text { Arginase } \\
\text { activity } \\
\text { (mean } \pm \mathrm{SE}) \dagger\end{array}$} \\
\hline & $\begin{array}{c}\text { No } \\
\text { supplement }\end{array}$ & $\begin{array}{c}50 \mathrm{mM} \\
\text { Arginine }\end{array}$ & $\begin{array}{c}50 \mathrm{mM} \\
\text { Ornithine }\end{array}$ & $\begin{array}{c}28 \cdot 5 \mu M \\
\text { P5C }\end{array}$ & $\begin{array}{c}87 \mu \mathrm{M} \\
\text { Proline }\end{array}$ & \\
\hline 8325 & \pm & + & + & + & + & $89 \cdot 4 \pm 6 \cdot 3$ \\
\hline $8325 \mathrm{Pro}^{+}$ & + & + & + & + & + & $77 \cdot 8 \pm 4 \cdot 9$ \\
\hline DT105 & - & \pm & + & + & + & $4 \cdot 7 \pm 0 \cdot 2$ \\
\hline DT112 & - & - & - & - & + & $65 \cdot 8 \pm 7 \cdot 6$ \\
\hline DT115 & - & - & - & - & + & $56 \cdot 6 \pm 2 \cdot 0$ \\
\hline DT116 & - & - & - & - & + & $67 \cdot 4 \pm 2 \cdot 3$ \\
\hline
\end{tabular}

* Glycerol defined medium minus proline agar plates with the indicated supplements were spot-inoculated using a loop and incubated at $37^{\circ} \mathrm{C}$ for up to $72 \mathrm{~h}$. +, strong growth after $24 \mathrm{~h}$; \pm , weak growth, isolated colonies, after $72 \mathrm{~h} ;-$, no growth after $72 \mathrm{~h}$.

† Arginase activity was assayed in late exponential phase liquid cultures in glycerol defined medium plus $50 \mathrm{mM} \mathrm{L}$-arginine, and activities are expressed as $\mathrm{nmol}$ ornithine produced $\min ^{-1}(\mathrm{mg} d r y \mathrm{wt})^{-1}$. The values for arginase activities are the results of 3-10 determinations.

activity in vitro in the wild-type and mutant strains failed to yield any positive results.

\section{Studies of $8325 \mathrm{Pro}^{+}$, a proline prototrophic variant of strain 8325}

Strain $8325 \mathrm{Pro}^{+}$is characterized by its ability to grow in the absence of proline without a long lag phase. The strain was originally isolated as a single colony of strain 8325 grown on a plate of glycerol defined medium lacking proline for $3 \mathrm{~d}$ at $37^{\circ} \mathrm{C}$ (Townsend \& Wilkinson, 1992). The strain has been maintained on glycerol defined medium lacking proline since. Cultivation of this strain in glycerol defined medium plus proline, followed by subculturing into medium minus proline did not restore the long lag phase to this strain. This suggests that the proline biosynthetic pathway in this strain is either permanently 'switched on', or is not repressed by the presence of proline in the growth medium. The arginase (Table 2) and ornithine aminotransferase activities of strain $8325 \mathrm{Pro}^{+}$were very similar to those of strain 8325 . These observations suggest that inducing proline biosynthesis in this strain does not involve increasing the expression of the arginase pathway.

When grown with $\mathrm{L}-\left[{ }^{14} \mathrm{C}\right]$ arginine in glycerol defined medium lacking proline, strain $8325 \mathrm{Pro}^{+}$accumulated 24926 c.p.m. (mg dry wt) ${ }^{-1}$ in the pool metabolites fraction, almost 15 times more than strain 8325 . Such a large pool of accumulated radioactivity suggests that arginine is taken up more effectively by strain $8325 \mathrm{Pro}^{+}$. Chromatography of the pool extract indicated that $28 \%$ of the radioactivity migrated with the same mobility as authentic proline (Fig. 3e). When strain $8325 \mathrm{Pro}^{+}$was grown with radiolabelled glutamate, 16540 c.p.m. (mg dry $w t)^{-1}$ accumulated. However, none of the radioactivity migrated as proline (Fig. 3f). These results support the idea that arginine, and not glutamate, serves as a precursor for proline biosynthesis in this strain.

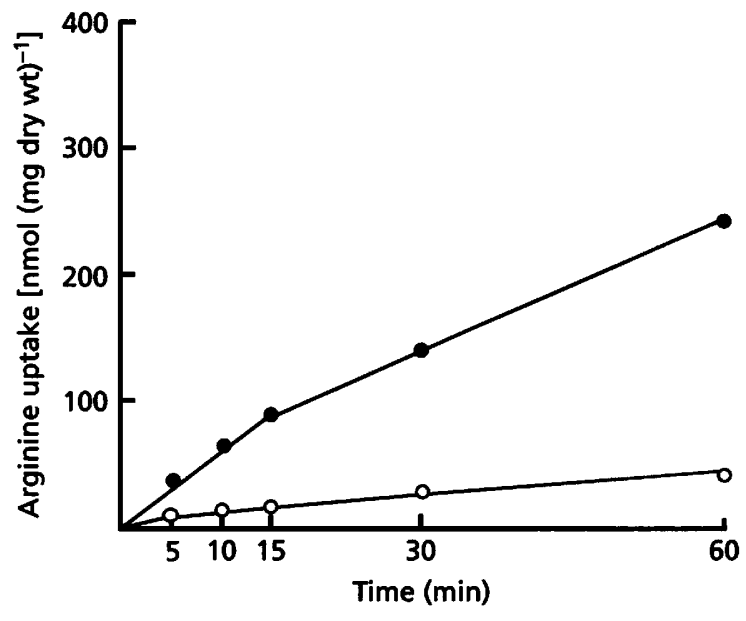

Fig. 4. Uptake of $L-\left[{ }^{14} \mathrm{C}\right]$ arginine by strains $8325(\mathrm{O})$ and 8325 Pro $^{+}(0)$. Radiolabelled $L-\left[{ }^{14} \mathrm{C}\right]$ arginine was added to midexponential phase cultures and uptake was measured by membrane filtration and scintillation counting.

\section{Arginine uptake studies}

The radioisotope studies demonstrated that strain 8325 $\mathrm{Pro}^{+}$accumulated much more radioactivity from L$\left[{ }^{14} \mathrm{C}\right]$ arginine than strain 8325 . Such an increase in the radioactive pool could arise from an increased rate of uptake of $\mathrm{L}-\left[{ }^{14} \mathrm{C}\right]$ arginine. The uptake of $\mathrm{L}-\left[{ }^{14} \mathrm{C}\right]$ arginine by strains 8325 and $8325 \mathrm{Pro}^{+}$from glycerol defined medium and glycerol defined medium minus proline, respectively, were measured (Fig. 4). After 15 min, strain $8325 \mathrm{Pro}^{+}$had accumulated about eight times more L$\left[{ }^{14} \mathrm{C}\right]$ arginine from the growth medium than had strain 8325. When the uptake of $\mathrm{L}-\left[{ }^{14} \mathrm{C}\right]$ arginine was measured in chloramphenicol-inhibited cultures where protein synthesis could not occur, strain $8325 \mathrm{Pro}^{+}$accumulated 5.9 times more $\mathrm{L}_{-}\left[{ }^{14} \mathrm{C}\right]$ arginine than strain 8325 . 
No difference in $\mathrm{L}-\left[{ }^{14} \mathrm{C}\right]$ glutamate accumulation was noted between the two strains (data not shown). These results suggest that strain $8325 \mathrm{Pro}^{+}$has responded to proline starvation by increasing its capacity to take up arginine from the medium.

Cultivation of $S$. aureus strain 8325 in the absence of proline results in the stimulation of an arginine to proline biosynthetic pathway. Strain $8325 \mathrm{Pro}^{+}$, which was obtained by cultivating strain 8325 on solid defined medium lacking proline, appears to be permanently switched on for a high expression of the arginine to proline pathway. S. aureus strains that require the presence of several amino acids can be 'trained' to grow in media containing progressively fewer amino acids (Archibald \& Heckels, 1975; Gladstone, 1937). Reversion from auxotrophy to prototrophy has also been described in lactobacilli, enterococci and pediococci (Deguchi \& Morishita, 1992; Morishita et al., 1974, 1981). Reversion is presumed to be due to single mutations. The basis for amino acid auxotrophy has been studied in various bacteria. In Sbigella dysenteriae, which is naturally auxotrophic for tryptophan, a promoter mutation reducing promoter function by $90 \%$ and a mutation in $\operatorname{trp} E$ were described (Miozzari \& Yanofsky, 1978). Neisseria gonorrboeae arginine auxotrophs contained a 3 bp deletion in the argJ gene (Martin \& Mulks, 1992). Recently, Godon et al. (1993) and Delorme et al. (1993) have compared gene sequences of leu and bis genes in dairy strains of Lactococcus lactis subsp. lactis, which are auxotrophic for the branched chain amino acids and histidine, with these genes from prototrophic strains isolated from non-dairy sources. The auxotrophic dairy strains, which were not able to revert to prototrophy, were not deleted for the leu and his genes in question but contained various nonsense mutations, frameshift mutations, deletions and mutations in the promoter region, depending on the gene under study. The prediction from the present study is that $S$. aureus is defective in the gene for $\gamma$-glutamyl kinase and/or glutamate$\gamma$-semialdehyde dehydrogenase encoding the enzymes involved in the conversion of glutamate to $\mathrm{P} 5 \mathrm{C}$.

The major difference related to proline biosynthesis observed in the proline prototroph S. aureus $8325 \mathrm{Pro}^{+}$ obtained from the proline 'auxotroph' 8325 appears to be an enhanced ability to transport arginine in the proline prototroph. To our knowledge this is the first instance where reversion to prototrophy may involve a transport protein rather than a biosynthetic enzyme. In related findings, Rahman \& Clarke (1980) described a strain of Pseudomonas aeruginosa unable to utilize L-lysine effectively as a carbon source due to low activity of a lysine permease. Mutants that grew well on lysine had active L-lysine uptake systems. The mechanism involved in producing the enhanced arginine transport activity in $S$. aureus is unclear at this time. Interestingly, in this connection, one of the characteristics of stationary phase bacteria, which can be regarded as bacteria starved for nutrients (Kolter $e t$ al., 1993), is that glucose and amino acid transport systems are induced during starvation (Faquin \& Oliver, 1984; Kolter et al., 1993). Obbink \& Campbell (1973) described increased proline transport in proline-starved $S$. aureus and Townsend \& Wilkinson (1992) showed that strain $8325 \mathrm{Pro}^{+}$had 3-5 times the activity of the high affinity proline transport system compared to strain 8325 . Arginine and ornithine utilization is defective in B. subtilis sigL mutants (Debarbouille et al., 1991). sigL encodes an alternative RNA polymerase $\sigma$ factor homologous to RpoN $\left(\sigma^{54}\right)$ in enteric bacteria. An ORF with significant homology to arginine permeases in other bacteria has been shown to be located in an operon dependent on the SigL $\sigma$ factor for expression (P. Glaser quoted in Fisher, 1993). Possibly, $S$. aureus $8325 \mathrm{Pro}^{+}$could be expressing an arginine transport system dependent on a starvationregulated alternative $\sigma$ factor. Interestingly, in enteric bacteria $\mathrm{RpoN}$ is involved in the response to nitrogen starvation.

A notable finding during these studies was that ornithine was more effective than arginine in supporting the growth of strain 8325 in the absence of proline. These results suggest a discrimination between the uptake of arginine and ornithine. Although surprising at first sight, these findings are compatible with knowledge of transport of the basic amino acids in $E$. coli, where at least three systems exist for the transport of arginine, lysine and ornithine (Steltes et al., 1992). One system, the argininespecific system, transports only arginine. A second system, (the LAO system) transports lysine and ornithine, and is inhibited by arginine, which is not a substrate of the LAO system. The third system is a lysine-specific permease. If a similar situation exists in $S$. aureus, our results could be explained by suggesting that ornithine is transported, by the LAO system, more efficiently than arginine in both strains. There are other arginine- and ornithine-related observations that may be relevant. Arginine/ornithine exchange systems have been described in various bacteria including Spiroplasma melliferum, lactic acid bacteria and $P$. aeruginosa (see Shirazi et al., 1995). Also, a staphylococcal siderophore, staphyloferrin A, has D-ornithine as a major structural component and addition of D-ornithine to iron-deficient medium stimulates siderophore production markedly (Konetschny-Rapp et al. 1990). Clearly, scope exists for clarification of basic amino acid transport in $S$. aureus.

The results presented in this paper from nutritional, radiolabelling, and mutant studies are consistent with the suggestion that in S. aureus, proline is biosynthesized from arginine and not glutamate, and that the transport of arginine into the cell and its catabolism through the arginase pathway probably play key roles in this process.

\section{ACKNOWLEDGEMENTS}

We are grateful to John Dailey and Bob Berger of the Department of Basic Sciences, University of Illinois College of Medicine at Peoria, for amino acid analyses. We are grateful to Peter Angeletti and Michelle Stroup for their help with some of the experiments. This work was supported by grant number 1 R15 GM42080-01A2 from the National Institutes of Health.

\section{REFERENCES}

Abdelal, A. T. (1979). Arginine catabolism by microorganisms. Annu Rev Microbiol 33, 139-168. 
Archibald, A. R. \& Heckels, J. E. (1975). Alterations in the composition and bacteriophage-binding properties of walls of Stapbylococcus aureus $\mathrm{H}$ grown in continuous culture in simplified defined medium. Biocbim Biopbys Acta 406, 60-67.

Baumberg, S. \& Klingel, U. (1993). Biosynthesis of arginine, proline and related compounds. In Bacillus subtilis and Other Gram-positive Bacteria, pp. 299-306. Edited by A. L. Sonenshein, J. A. Hoch \& R. Losick. Washington, DC: American Society for Microbiology.

Bildingmeyer, B. A., Cohen, S. A. \& Tarvin, T. L. (1984). Rapid analysis of amino acids using pre-column derivatization. $J$ Cbromatogr 336, 93-104.

Brandriss, M. C. \& Falvey, D. A. (1992). Proline biosynthesis in Saccharomyces cerevisiae: analysis of the pro3 gene, which encodes pyrroline-5-carboxylate reductase. $J$ Bacteriol 174, 3782-3788.

Christian, J. H. B. (1961). The effects of washing treatments on the composition of Staphylococcus aureus. Aust J Biol Sci 15, 324-332.

Cunin, R., Glansdorff, N., Piérard, A. \& Stalon, V. (1986). Biosynthesis and metabolism of arginine in bacteria. Microbiol Rev 50, 314-352.

Debarbouille, M., Martin-Verstraete, I., Kunst, I. \& Rapoport, G. (1991). The Bacillus subtilis sigL gene encodes an equivalent of sigma 54 from Gram-negative bacteria. Proc Natl Acad Sci USA 88, 9092-9096.

Deguchi, T. \& Morishita, T. (1992). Nutritional requirements in multiple auxotrophic lactic acid bacteria: genetic lesions affecting amino acid biosynthesis in Lactococcus lactis, Enterococcus faecalis and Pediococcus acidilactici. Biosci Biotechnol Biochem 56, 913-918.

Delorme, C., Godon, J. J., Ehrlich, S. D. \& Renault, P. (1993). Gene inactivation in Lactococcus lactis: histidine biosynthesis. $J$ Bacteriol 175, 4391-4399.

Emmett, M. \& Kloos, W. E. (1975). Amino acid requirements of staphylococci isolated from human skin. Can $J$ Microbiol 21, 729-733.

Faquin, W. C. \& Oliver, J. D. (1984). Arginine uptake by a psychrophilic marine Vibrio sp. during starvation-induced morphogenesis. J Gen Microbiol 130, 1331-1335.

Fisher, S. H. (1993). Utilization of amino acids and other nitrogencontaining compounds. In Bacillus subtilis and Otber Gram-positive Bacteria, pp. 221-228. Edited by A. L. Sonenshein, J. A. Hoch \& R. Losick. Washington, DC: American Society for Microbiology.

Gladstone, G.P. (1937). The nutrition of Stapbylococcus aureus: nitrogen requirements. Brit J Exp Patbol 18, 322-333.

Godon, J. J., Delorme, C., Bardowski, J., Chopin, M. C., Ehrlich, S. D. \& Renault, P. (1993). Gene inactivation in Lactococcus lactis: branched-chain amino acid biosynthesis. J Bacteriol 175, 4383-4390.

Graham, J. E. \& Wilkinson, B. J. (1992). Stapbylococcus aureus osmoregulation: roles for choline, glycine betaine, proline and taurine. J Bacteriol 174, 2711-2716.

Harwood, C. R. \& Baumberg, S. (1977). Arginine hydroxamateresistant mutants of Bacillus subtilis with altered control of arginine metabolism. J Gen Microbiol 100, 177-188.

Hayzer, D. J. \& Leisinger, T. (1981). Proline biosynthesis in Eschericbia coli. Biocbem $J$ 197, 269-274.

Jayaswal, R. K., Lee, Y.-I. \& Wilkinson, B. J. (1990). Cloning and expression of a Staphylococcus aureus gene encoding a peptidoglycan hydrolase activity. J Bacteriol 172, 5783-5788.
Kolter, R., Siegele, D. A. \& Tormo, A. (1993). The stationary phase of the bacterial life cycle. Annu Rev Microbiol 46, 855-874.

Konetschny-Rapp, S., Jung, G., Meiwes, J. \& Zahner, H. (1990). Staphyloferrin A: a structurally new siderophore from staphylococci. Eur J Biochem 191, 65-74.

Krasuski, A. (1981). Urea and arginine catabolism in $S$. aureus. I. Relationships. In Stapbylococci and Staphylococcal Infections, pp. 413-416. Edited by J. Jeljaszewicz. Stuttgart and New York: Gustav Fisher Verlag.

Laishley, E. J. \& Bernlohr, R. W. (1968). Regulation of arginine and proline catabolism in Bacillus licheniformis. J Bacteriol 96, 322-329.

Leisinger, T. (1987). Proline biosynthesis. In Eschericbia coli and Salmonella typhimurium: Cellular and Molecular Biology, Vol. 1, pp. 345-357. Edited by F. Neidhardt, J. L. Ingraham, K. Low, B. Magasanik, M. Schaechter \& H. Umbarger. Washington, DC: American Society for Microbiology.

Martin, P. R. \& Mulks, M. H. (1992). Molecular characterization of the argJ mutation in Neisseria gonorrboeae strains with requirements for arginine, hypoxanthine and uracil. Infect Immun 60, 970-975.

Miozzari, G. \& Yanofsky, C. (1978). Naturally occurring promoter down mutation: nucleotide sequence of the trp promoter/ operator/leader region of Shigella dysenteriae 16. Proc Natl Acad Sci US A 75, 5580-5584.

Morishita, T., Fukada, T., Shirota, M. \& Yura, T. (1974). Genetic basis of nutritional requirements in Lactobacillus casei.J Bacteriol 120, 1078-1084.

Morishita, T., Degushi, Y., Yajima, M., Saturai, T. \& Yura, T. (1981). Multiple nutritional requirement of lactobacilli: genetic lesions affecting amino acid biosynthetic pathways. $J$ Bacteriol 148, 64-74.

Mountain, A. \& Baumberg, S. (1980). Map locations of some mutations conferring resistance to arginine hydroxamate in Bacillus subtilis 168. Mol Gen Genet 178, 691-701.

Novick, R. P. (1991). Genetic systems in staphylococci. Methods Enzymol 204, 587-636.

Obbink, D. J. G. \& Campbell, J. J. R. (1973). Derepression of a proline transport system in Stapbylococcus aureus. Can J Microbiol 19, 397-401.

Rahman, M. \& Clarke, P. H. (1980). Genes and enzymes of lysine catabolism in Pseudomonas aeruginosa. J Gen Microbiol 116, 357-369.

Shirazi, I., Tarshis, M. \& Rottem, S. (1995). An arginine/ornithine exchange system in Spiroplasma melliferum. Microbiology 141, 2323-2328.

Steltes, C., Ellis, J., Wu, J. \& Rosen, B. P. (1992). The lys $P$ gene encodes the lysine-specific permease. $J$ Bacteriol 174, 3242-3249.

Townsend, D. E. \& Wilkinson, B. J. (1992). Proline transport in Staphylococcus aureus: a high affinity system and a low affinity system involved in osmoregulation. $J$ Bacteriol 174, 2702-2710.

Sambrook, J., Fritsch, E. F. \& Maniatis, T. (1989). Molecular Cloning: a Laboratory Manual, 2nd edn. Cold Spring Harbor, NY: Cold Spring Harbor Laboratory.

Williams, I. \& Frank, L. (1975). Improved chemical synthesis and enzymatic assay of pyrroline-5-carboxylic acid. Anal Biochem 64 , 85-97.

Received 9 August 1995; revised 3 January 1996; accepted 17 January 1996. 